\title{
When do Thick Venture Capital Markets Foster Innovation? An Evolutionary Analysis*
}

\author{
Luca Colombo $^{\dagger} \quad$ Herbert Dawid Kordian Kabus $^{\S}$
}

Preliminary Version - June 2006

\begin{abstract}
In this paper we examine the trade off between different effects of the availability of venture capital on the speed of technological progress in an industry. We consider an evolutionary industry simulation model based on Nelson and Winter (1982) where R\&D efforts of an incumbent firm generate technological know-how embodied in key R\&D employees, who might use this know-how to found a spinoff of the incumbent. Venture capital is needed to finance a spinoff, and therefore the expected profits from founding a spinoff depend on how easily venture capital can be acquired. Accordingly, thick venture capital markets might have two opposing effects. First, incentives of firms to invest in R\&D might be reduced and, second, if spinoff formation results in technological spillovers between the parent firm and the spinoffs, the generation of spinoff firms might positively influence the future efficiency of the incumbent's innovation efforts. We study how this tradeoff influences the effect of venture capital on the innovation expenditures, speed of technological change and the evolution of industry concentration in several scenarios with different industry characteristics.
\end{abstract}

Keywords: Venture Capital, Technological Progress, R\&D Effort, Spinoff, Industry Evolution

\section{Introduction}

It is well established that economic growth is to a considerable extent driven by technological change and therefore understanding the impact of economic factors on the speed of technological change is important to characterize the factors that foster economic growth. Attempts to characterize such factors can be made at different levels of aggregation (firm-level, industry-level, macroeconomic level). Much work has focused on the industry level studying patterns of co-evolution of industry structure, product range

\footnotetext{
*Financial support from the German Science Foundation (DFG) under grant GRK1134/1: International Research and Training Group 'Economic Behavior and Interaction Models (EBIM)' is gratefully acknowledged.

${ }^{\dagger}$ Università Cattolica del Sacro Cuore, Milano, Italy, E-mail: lucava.colombo@unicatt.it

${ }^{\ddagger}$ Deparment of Business Adminsitration and Economics and Institute of Mathematical Economics, Bielefeld University, Germany, Email: hadwid@wiwi.uni-bielefeld.de

${ }^{\S}$ Deparment of Business Adminsitration and Economics, Bielefeld University, Germany, Email: kordian.kabus@uni-bielefeld.de
} 
and employed technology (e.g. Dosi et al. (1995), Klepper (1996), Malerba and Orsenigo (1996)). The evolution of many industries is characterized by the emergence of a few local agglomerations of producers, where a main mechanism driving such an evolution is the entry of start-up firms founded by former high-level employees of incumbent firms (see e.g. Dorfmann (1983), Dahl et al. (2003), Klepper (2004)). Following Klepper (2001) we refer to such entrants as spinoff firms. Spinoffs have a strong tendency to locate close to the parent firm (see e.g. Sorenson (2003)) and accordingly sequences of spinoff formations yields the generation of geographically concentrated firm clusters. Furthermore, generation of spinoffs by key employees of incumbents is an important channel of knowledge diffusion. Due to the increased diversity in the industry generated by spinoff entries and the intensive knowledge flows between firms in local clusters, such agglomerations have positive impact on the speed of technological change.

Founding a start-up company requires in addition to industry-relevant know-how also financial resources. Due to the risky nature of start-up enterprises venture capital plays a key role for financing spinoff companies. Based on a large a data set of venture capital backed start-up companies Gompers et al. (2003) observe that about $45 \%$ of these enterprises were spinoffs of public companies. They also show that firms that had been backed by venture capital themselves are more likely to spawn a venture-capital backed spinoff than companies who did not rely on venture capital. Accordingly, the availability of venture capital in a certain region is an important factor to facilitate the founding of spinoffs of local incumbents and the generation of a local agglomeration of firms. In addition to the positive effect of the emergence of agglomerations for technological change the inflow of venture capital into the industry should have a positive impact by itself, since additional resources become available to be spent on $\mathrm{R} \& \mathrm{D}$ and innovation related activities. There is empirical evidence that venture capital investments and also the availability of venture capital is not uniform across regions (see e.g. Sorenson and Stuart (2001) or Botazzi et al. (2004)) and therefore availability of venture capital is an indicator for the economic conditions in a given region. Following the line of reasoning sketched above, easy availability of venture capital is generally considered as an important factor facilitating innovative activity in a region and technological change ${ }^{1}$.

From the point of view of the parent company the foundation of a spinoff however has at least two negative implications. First, key employees leave the company, reducing the stock of know how embedded in the company ${ }^{2}$. Second, the spinoff is an additional competitor with a high level of know-how the generation of which has been financed by the parent company. This suggests that, at least if short run effects are considered, parent firms have incentives to keep the key personnel within the firm by offering additional remuneration for these employees. The better the outside option for the potential spinoff founders, the higher is the additional remuneration needed to keep the employee in the firm and the larger is the danger that the spinoff will actually be founded. Accordingly, incentives for firms to invest in order to generate know-how to be embedded in their key employees become smaller the easier potential entrepreneurs

\footnotetext{
${ }^{1}$ Amount of early stage venture financing is for example one of the key indicators in the country reports of the European Innovation Scoreboard published annually by the European Commission.

${ }^{2}$ Phillips (2002) uses data from Silicon Valley law firms to show that a 'parenting event' reduces the life chances for the parent firm.
} 
can access venture capital financing ${ }^{3}$. On the other hand, in the medium and long run the incumbent firm might profit from the existence of a local cluster and the knowledge externalities generated by activities of the other cluster firms. This is particularly true if main competitors of the firm are located in distinct regions or firm clusters.

The aim of this paper is, to shed more light on the trade-off between the direct and strategic effects described above and to study the influence of the availability of venture capital on incumbent firms' choices of R\&D effort and on the evolution of technology and structure of an industry. Clearly, the type of dependency between availability of venture capital and industry evolution might crucially depend on specifics of the industry like the properties of the production technology, demand conditions, degree of knowledge orientation or intensity of knowledge exchange between producers. In order to distinguish between different types of industries we will consider two key aspects. First, the intensity of technological spillovers between firms in the industry that are located in the same geographical region. Second, the degree of advantages on the market established firms have compared to new entrants. To capture such advantages we consider learning curve effects. Marginal production costs are assumed to decrease as accumulated past output of the firm increases. We are aware that a classification of industries along these two dimensions is overly simplistic, but, given that these are very basic properties of the industry, we believe that considering these two dimensions allows for general insights into the main mechanisms responsible for the effects of venture capital availability on the speed of technological change. The main questions we address are:

- For what kind of industries does improved availability of venture capital increase the speed of technological change?

- For what kind of industries does improved availability of venture capital lead to higher firm expenditures for innovative activities?

- What is the impact of improved availability of venture capital on the dynamics of industry concentration and industry profits?

Since local availability of venture capital is often formulated as an economic policy goal, gaining insights into these issues also has clear implications for the design of innovation policy and competition policy.

In order to deal with the questions posed above we consider a dynamic agent-based industry simulation model that builds on the evolutionary model of Schumpeterian competition described in Nelson and Winter (1982). Variations of that model have been used in the past to study numerous aspects of industry evolution, see Dawid (2006) for a discussion of that stream of literature. In our setup an industry is considered

\footnotetext{
${ }^{3}$ There is some theoretical work on the effect of the threat of outgoing technological spillovers due to employee mobility on firms innovative efforts. Starting with Pakes and Nitzan (1983) different aspects of the optimal design of contracts for key R\&D employees under the threat of exit of that personnel has been studied (e.g. Anand and Galetovic (2000), Baccara and Razin (2004)). Gersbach and Schmutzler (2003) show in a static game theoretic model that potential worker mobility indeed has negative effects on equilibrium investments in innovative activities and Böhm and Colombo (2006) point out that in a general equilibrium framework potential worker mobility discourages adoption of better technologies by the incumbent firms.
} 
where firms located in several distinct industrial clusters produce with heterogenous technologies for a common market. Initially there is one firm in each cluster, additional firms might enter if spinoffs emerge from an existing firm in the cluster. There are technological spillovers within each cluster but none between the different clusters. Each firm can make investments for (process) innovation to generate new knowledge and improve its productivity. Productivity can also be improved by imitation of more productive competitors. Knowledge generated by innovative activities is assumed to be embodied in a key employee ${ }^{4}$ and if the innovation is sufficiently substantial the latter considers to found a spinoff that will then compete in the market based on that innovation. In order to do so, however, she needs venture capital. The easier it is to raise this capital the larger is the fraction of market profits of the new firm that can be attained by the spinoff founder. If the employee leaves the parent firm, only a fraction of the knowledge generated through the firms innovative activities remains with the incumbent, which would then suffer a reduction in productivity and profits. The parent firm can try to prevent the key employee from founding a spinoff by offering her a wage increase. The size of the offered wage premium and the employees decisions whether to accept it depends on the estimated profits of both sides in case a spinoff is formed and therefore on the costs for the employee associated with raising the necessary venture capital. Estimations of profits after spinoff formation are based on observations following previous spinoff entries.

Firms over time adapt their decisions concerning expenditures for innovation and imitation based on the comparison of the productivity gain per unit spent for the two activities in the past. This simple learning rule of reinforcement type allows to capture the potential negative effect of availability of venture capital on firms incentives to invest in innovative activities. Firms exhibit no strategic behavior in a game-theoretic sense but act strictly rule-based. Nevertheless, this type of model allows us to examine in a dynamic framework the tradeoff between the static and inter-temporal incentive effects as well as the dynamic externalities due to cluster emergence induced by the availability of venture capital.

In this paper we restrict the role of venture capital to providing necessary financial means for spinoff generation. This simplification ignores several other influences of venture capital financing like the facilitation of professionalization measures (see Hellman and Puri (2002)), which could influence relative performance if we considered scenarios where only a fraction of startups is financed by venture capital. In our model all new entries are financed by venture capital and we do not have to consider such effects. On the other hand, the results we obtain concerning the effect of improved availability of venture capital would also apply to the improvement of any other local resource that facilitates the generation of spinoffs.

In a related paper Colombo and Dawid (2006) have analyzed the impact of availability of venture capital on innovative activities of incumbents in a static game-theoretic framework focusing on the interaction between one incumbent and one potential spinoff founder. Due to the static nature of their analysis neither inter-temporal effects of cluster formation nor learning curve effects have a role, but the model is very similar to the one considered here with respect to the structure of the negotiations between the

\footnotetext{
${ }^{4}$ This could also be a group of senior employees that considers to leave the firm in order to found a spinoff.
} 
incumbent and its key employee. A main finding in Colombo and Dawid (2006) is that higher availability of venture capital has negative effects on incumbents' R\&D expenditures as long as the venture capital market is relatively thin, but this negative effect disappears as access to venture capital becomes very easy. The analysis in this paper allows us to see in how far these findings are qualitatively robust with respect to relaxed assumptions of rationality of firms and individuals and with respect to a dynamic perspective. This will be done by comparing the insights from Colombo and Dawid (2006) with the qualitative features of the simulation results for a baseline case where neither spillovers nor learning curve effects are present.

The paper is organized as follows. In Section 2 we present the agent-based simulation model. Simulation results are presented in section 3, where we distinguish between four different cases based on presence or absence of spillovers and learning curve effects. Concluding remarks are given in section 4 .

\section{The Model}

We consider a dynamic industry model that is based on the evolutionary model of Schumpeterian competition developed by Nelson and Winter (see Nelson and Winter (1982)). Using this kind of model implies that we abstract from product innovations and restrict attention to productivity increasing process innovations. This focus is certainly debatable, in particular because the motivation for a large fraction of spinoffs is the production of a new product not offered by the parent. On the other hand, the main competition effect we like to capture - spinoff generation reduces the incumbents profit in the short run - is captured in this formulation and dealing with product innovations would require to consider a substantially more involved demand structure and more refined innovation strategies.

\subsection{Production and Technical Change}

The industry consists of $N_{t}$ producers which all offer a homogenous good. Time is discrete and the number of producers might change over time due to the creation of new firms (see below).

As in Nelson and Winter (1982) we assume that each firm produces with constant returns to scale and fixed input coefficients, where the output quantity is determined by size and productivity of the current capital stock. The output of firm $i$ in period $t$ therefore reads

$$
Q_{i t}=K_{i t} A_{i t},
$$

where $K_{i t} \geq 0$ denotes the size of the capital stock of firm $i$ at $t$ and the productivity of capital, $A_{i t}>0$, is determined by the technology currently used by firm $i$. The total output $Q_{t}=\sum_{i=1}^{N_{t}} Q_{i t}$ induces the market price by the iso-elastic inverse demand function

$$
p_{t}=p\left(Q_{t}\right):=\frac{\alpha}{Q_{t}}, \alpha>0 .
$$

Production costs are given by $C_{i t} K_{i t}$, where

$$
C_{i t}=(1-\eta)^{n_{i t}} c
$$


with $\eta \in[0,1), c>0$ and

$$
n_{i t}=\frac{\ln \left(\sum_{s=1}^{t} Q_{i s}\right)}{\ln (2)}
$$

The corresponding unit costs read $\frac{C_{i t} K_{i t}}{Q_{i t}}=\frac{(1-\eta)^{n} i t \beta}{A_{i t}}$. For $\eta>0$ there are learningcurve effects that imply that every doubling of aggregate output leads to the reduction of unit costs of production by the factor $1-\eta$. Such learning curve effects might be driven by a reduction of the amount of complementary input factors (e.g. labor) that is needed per unit of capital. As pointed out in the introduction, the existence of learning curve effect is considered as a proxy for more general market advantages for incumbents compared to new entrants. Apart from learning curve effects such advantages might for example be due to advantageous conditions with suppliers or distributors, scale effects or consumer loyalty.

Firms can improve the productivity of capital by means of innovation or imitation. We denote by $X_{i t}^{i m}$ firm i's expenditures per unit of capital for imitation efforts in period $t$ and by $X_{i t}^{i n}$ expenditures per capital for innovation. Both types of efforts are assumed to have uncertain success, where the probabilities for successful imitation respectively innovation are given by

$$
\begin{aligned}
\mathbb{P}\left(I_{i t}=1\right) & =a_{i m} X_{i t}^{i m} K_{i t} \\
\mathbb{P}\left(I_{i t}=1\right) & =a_{i n} X_{i t}^{i n} K_{i t}+Y_{i t} .
\end{aligned}
$$

Here $I m_{i t}$ and $I n_{i t}$ are binary variables indicating the success of firm i's efforts in period $t$ and $a_{i m}, a_{i n}>0$ are sufficiently small to keep the expressions for the success probabilities in the unit interval. The term $Y_{i t}$ captures incoming technological spillovers for firm $i$. We assume that a firm can obtain spillovers only from competitors in its own industrial cluster. The cluster of firm $i$, denoted by $\mathcal{C}_{i t}$, consists of all firms that are either direct or indirect parents or direct or indirect spinoffs of firm $i$ (see below). The size of the spillovers depends on the innovation efforts of all other firms in the cluster with an upper bound given by $\beta>0$. In particular, we have

$$
Y_{i t}=\min \left[\beta, \beta a_{i n} \sum_{j \in \mathcal{C}_{i t} \backslash\{i\}} X_{j t}^{i n} K_{j t}\right] .
$$

As in Nelson and Winter (1982), successful imitation means that firm $i$ adopts the best technology that is currently used in the industry, whereas the productivity of a new technology stemming from a successful innovation is a stochastic variable with expected value equal to the firm's current productivity. We denote the productivity resulting from successful imitation by $\bar{A}_{t}=\max \left[A_{i t} \mid i=1, \ldots, N_{t}\right]$. The productivity of the new technology arising from a successful innovation is denoted by $\tilde{A}_{i, t}$ and follows a Gaussian distribution with mean $A_{i, t}$ and variance $\sigma^{2}$.

\subsection{Radical Innovations and Potential Spinoff Formation}

If a successful innovation effort of a firm leads to an improved productivity $\tilde{A}_{i t}>\bar{A}_{t}+\nu$ for a given $\nu>0$ we call this a radical technological innovation. In such a case the key $\mathrm{R} \& \mathrm{D}$ personnel of the firm considers to use the acquired knowledge in order to found 
a separate producing firm. If such a spinoff is indeed generated, the new firm $j$ enters the industry with $K_{j, t}=K_{i n i}$ and productivity of capital of $A_{j, t+1}=\tilde{A}_{i t}$. In such a case the parent company looses the tacit knowledge of the leaving R\&D personnel and therefore cannot fully exploit the newly developed technology. Productivity of capital only increases to the level

$$
A_{i, t+1}=\hat{A}_{i, t}:=A_{i t}+\mu\left(\tilde{A}_{i t}-A_{i t}\right) .
$$

On the other hand, if no spinoff is formed - which is always true if innovation activities are not successful or the innovation is not radical - the productivity of firm $i$ in the following periods is given by

$$
A_{i, t+1}=\max \left[A_{i t}, I m_{i t} \bar{A}_{t}, I n_{i t} \tilde{A}_{i t}\right] .
$$

Spinoffs are financed by venture capital, which means that for the first $\tau$ periods of existence the newly founded firm is not subject to any financial constraints on investments. Founders of the spinoff and venture capitalists split the profits of the new firm, where a fraction $\gamma$ of profits goes to the founders. The parameter $\gamma$ is a proxy for the bargaining power of the potential spinoff founders when negotiating with the venture capitalists. The larger the supply of venture capital on the market the larger should the bargaining power of the spinoff founder be. A scenario with few sources for venture capital accordingly corresponds to a small value of $\gamma$, whereas a large $\gamma$ corresponds to a thick venture capital market. The spinoff firm is added to the cluster of the parent firm which is now also the cluster of the spinoff firm.

In order to prevent their R\&D personnel from forming a spinoff the mother company can offer additional bonus payments. The size of this bonus is determined by bilateral bargaining, where the disagreement payoff for the employees is given by their share of estimated future profits if the spinoff is formed, and the disagreement payoff for the firm is given by its expected profit $\backslash$ losses in case the spinoff enters the market. In particular, denote by $\bar{\pi}^{S p}(t)$ the average per period profit per unit of capital in the time interval $[t-\eta, t-1]$ made by all spinoffs that have been in existence for more than $\tau$ periods. Furthermore, denote by $\bar{K}_{t}$ the average capital stock of all firms in period $t$. The potential spinoff founder estimate the per period profit potential of their spinoff, once it is established, as $\bar{\pi}^{S p}(t) \bar{K}_{t}$ and therefore estimate their payoffs in case of disagreement as

$$
b_{\min }=\gamma \bar{\pi}^{S p}(t) \bar{K}_{t} .
$$

They will not accept any bonus below this level. On the other hand, the firm estimates its next period profits in case a spinoff respectively no spinoff is formed as

$$
\begin{aligned}
\hat{\pi}_{i t}^{S p} & =\left(p\left(Q_{-i, t}+K_{i t} \hat{A}_{i t}\right) \hat{A}_{i t}-\hat{C}_{i, t+1}^{S p}-X_{i, t+1}^{i m}-X_{i, t+1}^{i n}\right) K_{i, t+1} \\
\hat{\pi}_{i t}^{N S p} & =\left(p\left(Q_{-i, t}+K_{i t} \tilde{A}_{i t}\right) \tilde{A}_{i t}-\hat{C}_{i, t+1}^{N S p}-X_{i, t+1}^{i m}-X_{i, t+1}^{i n}\right) K_{i, t+1},
\end{aligned}
$$

where the estimated per capital costs of production $\hat{C}_{i, t+1}^{S p}, \hat{C}_{i, t+1}^{N S p}$ in general differ because of the differences in learning curve effects induced by different output quantities. The maximal bonus the firm would be willing to accept is

$$
b_{\max }=\hat{\pi}_{i t}^{S p}-\hat{\pi}_{i t}^{N S p} \text {. }
$$


If we assume that the actual bonus is determined by the Nash Bargaining solution of this bargaining problem with bargaining power $\xi$ for the firm, we obtain that a spinoff is formed whenever $b_{\min }>b_{\max }$. If $b_{\min } \leq b_{\max }$ no spinoff is formed and the bonus reads

$$
b_{i t+s}=\xi b_{\min }+(1-\xi) b_{\max }, \xi \in[0,1] \quad s=1, \ldots d .
$$

The firm commits to pay this bonus to the $\mathrm{R} \& \mathrm{D}$ employees each period from $t+1$ to $t+d$.

\subsection{Capital Accumulation, Savings and External Financing}

Profits per unit of capital are denoted by $\pi_{i t}$ and read

$$
\pi_{i t}=p_{t} A_{i t}-C_{i t}-X_{i t}^{i m}-X_{i t}^{i n}-b_{i, t} .
$$

$B_{i t}$ captures special bonus payments the firm might have to pay in order to keep their key R\&D manager within the firm. Details concerning $B_{i t}$ are discussed. In case profits are positive a fraction $\lambda$ is distributed as dividends. Not distributed profits net of investments are saved. Denoting investments by $I_{i t}$ and firm savings by $S_{i t}$ we have

$$
S_{i t}= \begin{cases}S_{i, t-1}+(1-\lambda) \pi_{i t}-I_{i t} & \pi_{i t} \geq 0 \\ S_{i, t-1}+\pi_{i t}-I_{i t} & \pi_{i t}<0 .\end{cases}
$$

Capital is assumed to depreciate at a rate $\delta>0$ for all firms, i.e.

$$
K_{i, t+1}=(1-\delta) K_{i t}+I_{i t} K_{i t} .
$$

Investment of firms is determined on the one hand by the their intended investment pattern and, on the other hand, by financial constraints. The intended investment per unit of capital of firm $i$ is given by

$$
\hat{I}_{i t}=\max \left[0, \delta+1-\frac{2-M S_{i t}}{2 P C_{i t}\left(1-M S_{i t}\right)}\right],
$$

where $M S_{i t}=Q_{i t} / \sum_{j=1}^{N_{t}} Q_{j t}$ denotes the market share of firm $i$ and $P C_{i t}=\left(p_{t} A i t\right) / C_{i t}$ the price-cost ratio. The reader is referred to Nelson and Winter (1982) for a discussion of the rationale underlying this particular form of the intended investment function. All firms other than startups financed by venture capital finance investments by profits plus savings. If a firm cannot cover the intended net investments by profits plus savings it can however obtain external financing as long as profits are positive. Hence, financial constraints for investments are given by

$$
f\left(\pi_{i t}\right)= \begin{cases}S_{i t}+\delta+\pi_{i t} & \pi_{i t}<0 \\ S_{i t}+\delta+3.5 \pi_{i t} & \pi_{i t} \geq 0 .\end{cases}
$$

and actual investments read

$$
I_{i t}=\min \left[\hat{I}_{i t}, f\left(\pi_{i t}\right)\right]
$$

Financial constraints for investments are never binding for the first $\tau$ periods of operation of spinoff companies that are financed by venture capital. In these cases we have $I_{i t}=\hat{I}_{i t}$. 


\subsection{Adaptation of Strategies}

Firms adapt over time their strategies concerning investments for imitative and innovative activities. The spirit of the used adaptation rule is similar to reinforcementlearning. A firm updates $X_{i t}^{i m}$ and $X_{i t}^{i n}$ after every period where it had either a successful imitation or innovation based on the relative average returns on the two types of investment. We denote by $\Delta_{i t}^{i n}$ and $\Delta_{i t}^{i m}$ the estimates of firm $i$ of the returns on investment for innovation and imitation investments. These estimates stay unchanged from one period to the next if the corresponding activity had no success in that period. Assume that firm $i$ had a successful innovation in period $t-1$ and that the last successful innovation before that was in period $t-k$. Then, based on a comparison of the profitability of the innovation and the total investments needed to generate it, the estimated return on investment for innovations is updated to

$$
\Delta_{i t}^{i n}=\frac{\left(A_{i t}-A_{i, t-1}\right) p_{t}-b_{i t}}{\sum_{s=t-k+1}^{t-1} X_{i t}^{i n}} .
$$

Analogously, if a successful imitation occurred in $t-1$ the return on investment for imitation is updated to

$$
\Delta_{i t}^{i m}=\frac{\left(A_{i t}-A_{i, t-1}\right) p_{t}}{\sum_{s=t-k+1}^{t-1} X_{i t}^{i m}} .
$$

If an innovation or imitation occurred in $t-1$ the firm compares the the updated return on investment with that of the competing activity. The investments for the activity with the higher estimated return are increased by a given percentage, whereas investments for the activity with the lower estimated return are reduced. We have

$$
\begin{aligned}
& \left.\begin{array}{l}
X_{i, t+1}^{i n}=(1-\epsilon) X_{i t}^{i n} \\
X_{i, t+1}^{i m}=(1+\epsilon) X_{i t}^{i m}
\end{array}\right\} \\
& \left.\begin{array}{l}
X_{i, t+1}^{i n}=(1+\epsilon) X_{i t}^{i n} \\
X_{i, t+1}^{i m}=(1-\epsilon) X_{i t}^{i m}
\end{array}\right\} \quad \Delta_{i t}^{i n}<\Delta_{i t}^{i m} \\
& \Delta_{i t}^{i n}>\Delta_{i t}^{i m} .
\end{aligned}
$$

In figure 1 we give an overview over the sequence of activities in a given period $t$.

\section{Results}

\subsection{Simulation Setup}

All reported results are based on batches of 50 simulation runs with $T=200$ periods for each parameter constellation. To check whether a change in the parameter setting has significant effects on the means over the 50 runs of some considered variables, we have backed our qualitative statements with Wilcoxon signed rank tests typically using a significance level of 0.95. In particular, all qualitative statements concerning monotonicity of productivity with respect to $\gamma$ have been confirmed using a Wilcoxon test to compare scenarios with $\gamma=0$ and $\gamma=1$. The main focus of our analysis is on the interplay of the parameters $\gamma$ indicating the availability of venture capital, $\eta$ 
Production Quantitiy: $Q_{i t}=A_{i t} K_{i t}$

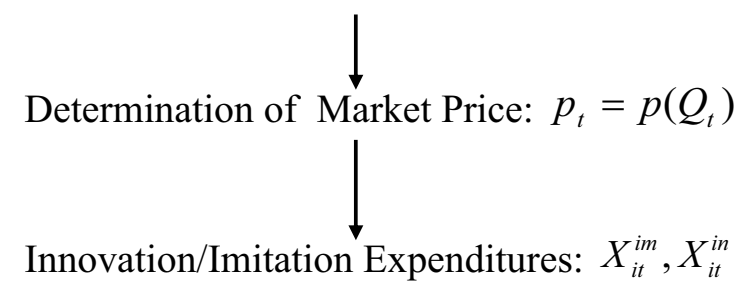

Profits: $\pi_{i t}=p_{t} A_{i t}-C_{i t}-X_{i t}^{i m}-X_{i t}^{i n}-b_{i t}$

$\downarrow$

Investments: $I_{i t}$

Capital Accumulation, Accumulation of Savings

$\downarrow$

Successful Innovation / Imitation?
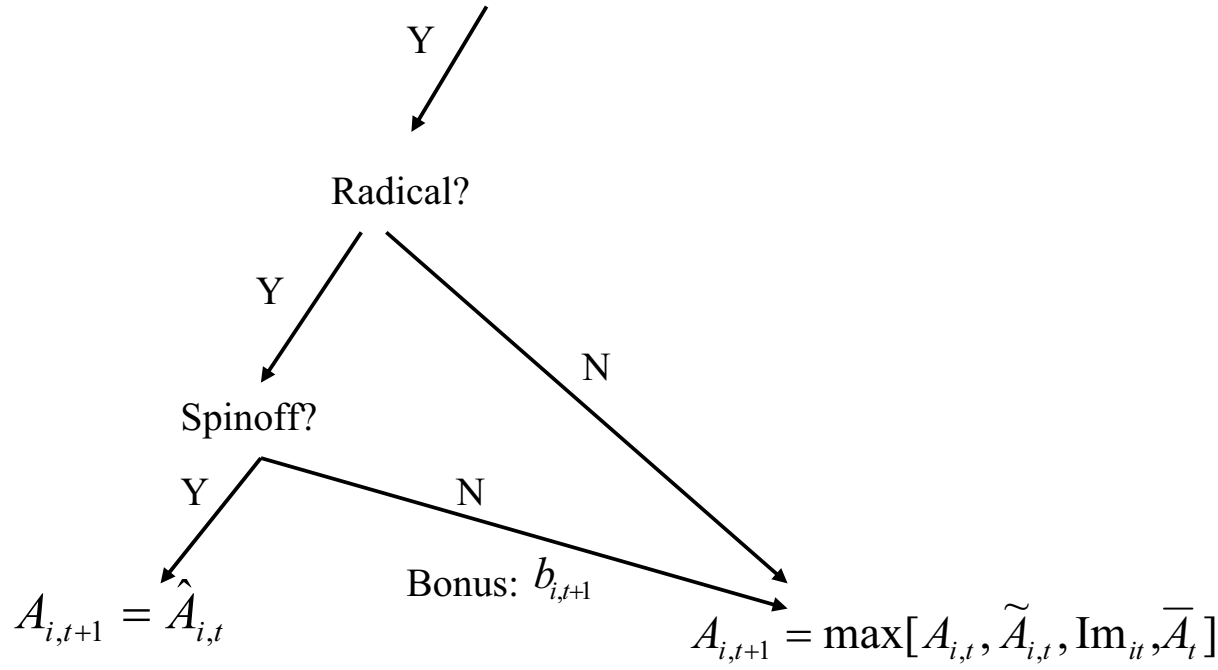

$\downarrow$

If succ. Innov. or Imit. in t-1: Updating of $X_{i, t+1}^{i m}, X_{i, t+1}^{i n}$

Figure 1: Sequence of events in a given period $t$ 
determining the strength of the learning curve effect and the spillover intensity $\beta$. The default parameter setting for the other model parameters is given by

$$
\begin{array}{lll}
\alpha=100 & a_{i m}=0.125 & a_{i n}=0.125 \\
c=0.16 & \sigma=0.02 & \lambda=0.2 \\
\epsilon=0.1 & \delta=0.03 & \nu=0.02 \\
\mu=0 & \xi=0.5 & \tau=10 \\
d=10 & X_{i 0}^{i m}=0.005 & X_{i 0}^{i n}=0.005 \\
K_{i 0}=89.7 & K_{i n i}=10 &
\end{array}
$$

Changes in these parameters have been considered and did not result in qualitative changes of the obtained insights. As far as technological spillovers and learning curve effects go, we consider four scenarios: i) neither effect is present; ii) positive learning curve effects, no spillovers; iii) positive spillovers, no learning curve effects; iv) both effects are present. In consideration of the main questions posed in the introduction we report for each of the four scenarios the impact of the availability of venture capital on several key variables:

- average productivity at $T: A(t)=\sum_{i=1}^{N_{t}} \frac{K_{i t}}{K_{t}^{\text {cum }}} A_{i t}$

- average innovation and imitation investments at $T: X^{i m}(t)=\sum_{i=1}^{N_{t}} \frac{K_{i t}}{K_{t}^{c u m}} X_{i t}^{i m}$, $X_{t}^{i n}=\sum_{i=1}^{N_{t}} \frac{K_{i t}}{K_{t}^{\text {cum }}} X_{i t}^{i n}$

- average firm profits at $T: \Pi(t)=\sum_{i=1}^{N_{t}} \frac{K_{i t}}{K_{t}^{\text {cum }}} \pi_{i t} K_{i t}$

- industry concentration (Herfindahl Index) at $T: H H(t)=\sum_{i=1}^{N^{t}}\left(\frac{Q_{i t}}{Q_{t}^{c u m}}\right)^{2}$,

where $K_{t}^{\text {cum }}$ and $Q_{t}^{\text {cum }}$ denote total capital stock respectively total output in the industry at time $t$.

\subsection{The Baseline Case}

Let us first consider the scenario without knowledge externalities within a cluster and without learning curve effects. Both of these effects are of genuine dynamic nature and therefore have not been considered in the static game-theoretic analysis in Colombo and Dawid (2006). Before we systematically examine the impact of an increase in $\gamma$ on the state of the industry after $T=200$ periods, we illustrate in figure 2 some basic pattern of the dynamics arising in the model. In particular, we show the trajectories of productivity and market share of all firms for one example of a run with low availability $(\gamma=0.25)$ and one example of a run with high availability $(\gamma=0.75)$ of venture capital. The trajectories of all firms belonging to the same cluster are depicted in the same color. 


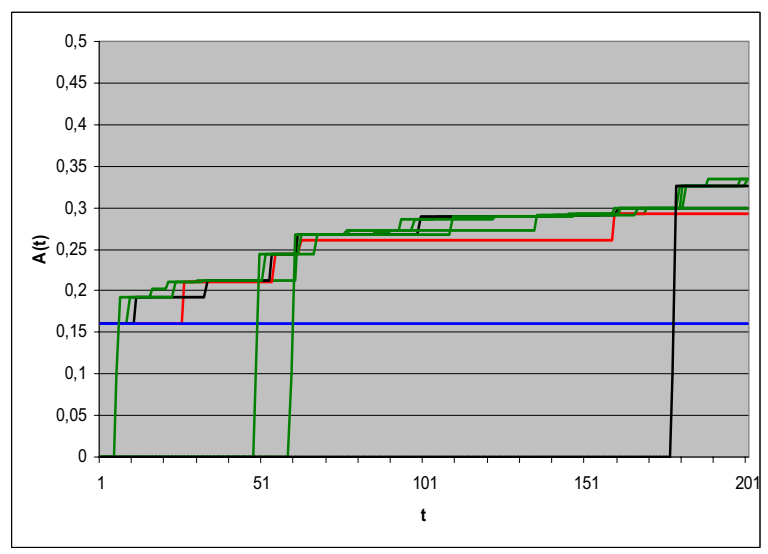

(a)

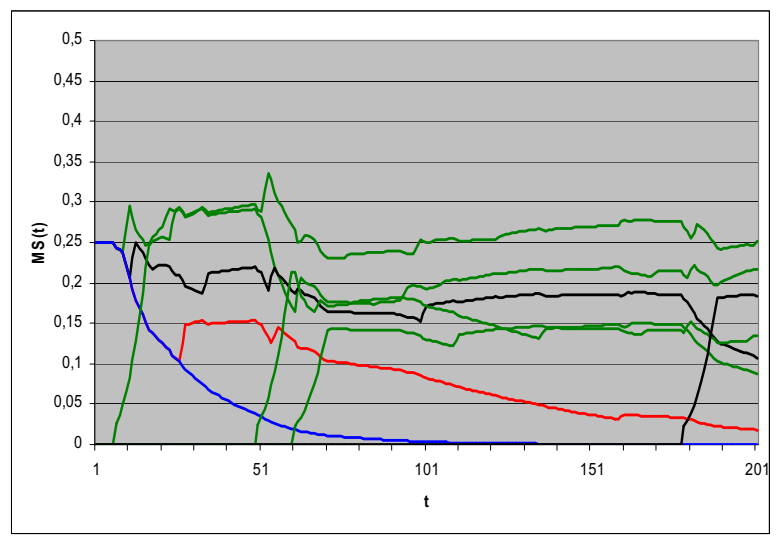

(c)

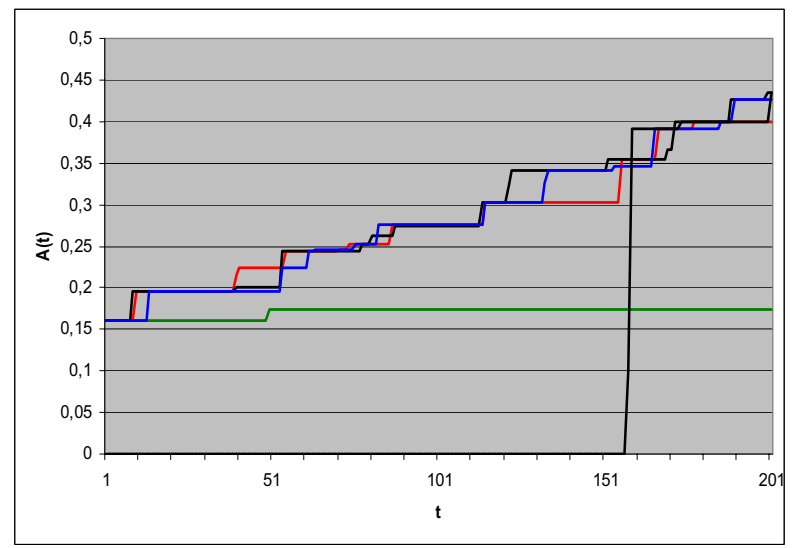

(b)

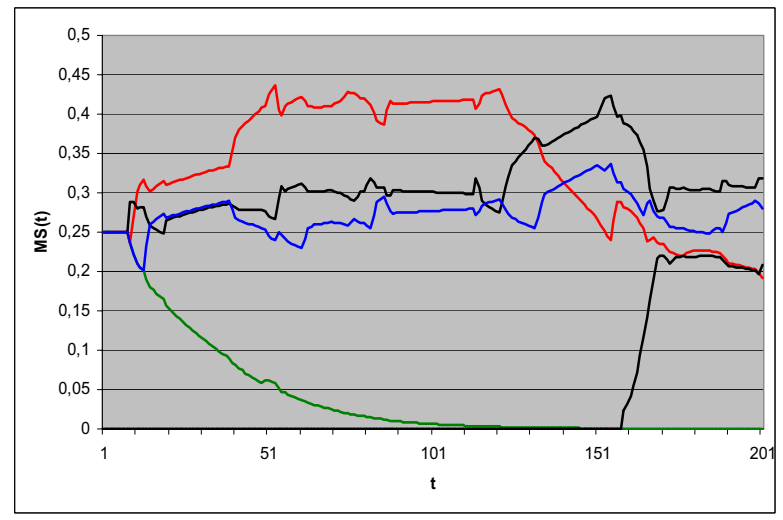

(d)

Figure 2: Trajectories of firms' productivity and market shares for a single run $(\beta=$ $\eta=0$ ) with $\gamma=0.75$ (panels (a) and (c)) and with $\gamma=0.25$ (panels (b) and (d))

Several observations can be made at this point. As far as the evolution of productivity goes, the observed pattern of small stepwise technological improvements by single firms with relatively fast imitation by the competitors is quite familiar from previous analyses of Nelson-Winter type models. With the exception of a few laggards the variance of the productivity of firms stays small. As has to be expected, the number of spinoffs is larger in the case where venture capital is more readily available. Considering market-shares it can be seen that spinoffs quickly acquire substantial market shares and are able to keep these shares after the venture capital financing expires. Furthermore, a clear negative effect on the market share of the mother firm of the spinoff can be seen such that the positive effect of the foundation of a spinoff on the total market share of all firms in that cluster is only minor.

Comparing panels (a) and (b) one observes that productivity after $T$ periods is larger for $\gamma=0.25$ than for $\gamma=0.75$. At first sight this is rather surprising since a 
larger number of spinoffs means that a larger amount of venture capital has flown into the industry which should increase total revenues and accordingly total expenditures for innovation. On the other hand, the strategic analysis in Colombo and Dawid (2006) suggest that increased availability of venture capital reduces incentives for firms to invest in innovative activities. Before we explore this type of explanation we have to verify that the observation in these two single runs corresponds to a robust general effect. In table 1 we give the median values over 50 runs of the average productivity in the industry after $T$ periods for values of $\gamma \in\{0,0.25,0.5,0.75,1\}^{5}$. It can be seen

\begin{tabular}{|c|ccccc|}
\hline$\gamma$ & 0 & 0.25 & 0.5 & 0.75 & 1 \\
\hline$A(T)$ & 0.45 & 0.43 & 0.41 & 0.41 & 0.4 \\
\hline
\end{tabular}

Table 1: Median values of average productivity in the industry after $T$ periods for $\beta=\eta=0$.

that for small $\gamma$ average productivity $A(T)$ is decreasing for increasing $\gamma$ but becomes virtually constant in the region of high availability of venture capital. Although the differences in the median are small, the difference in the $A(T)$ values between runs with $\gamma=0$ and such with $\gamma=1$ is statistically significant at a $95 \%$ level. To check whether the negative effect of availability of venture capital on productivity is indeed due to the reduced incentives to invest in innovation, we give in figure 3 the average expenditures per capital unit in the industry for innovation and imitation. Indeed, it can be clearly seen that as $\gamma$ goes up firms shift their activities more towards imitation and reduce their expenditures for innovation. Again, this phenomenon disappears as $\gamma$ becomes large. This might be due to the fact that for large values of $\gamma$ almost every radical innovation results in the generation of a spinoff. Under the assumption that no potential spinoff founder will be kept in the firm by bonus payments the actual value of $\gamma$ does no longer influence the payoff of the incumbent firm and therefore also not its incentives to invest in innovative activities. These observations match very well the findings concerning innovation incentives in Colombo and Dawid (2006). In that respect it should be noted that contrary to Colombo and Dawid (2006) in our settings firms do not act strategically and do not build estimations about future returns on investment. Nevertheless, the relevant strategic aspects are captured in this evolutionary model with simple reinforcement-type learning behavior of firms.

In figure 4(a) it can be seen that average firm profits decrease for increasing values of $\gamma$. The strong effect of $\gamma$ on industry concentration (figure 4(b)) suggests that the negative effect of $\gamma$ on average productivity is not the main driver of this phenomenon, but rather the increased competition due to the larger number of spinoff firms.

\subsection{The Impact of Learning Curve Effects}

Learning curve effects imply comparative cost advantages of incumbents compared to spinoff firms. Accordingly, one could expect that incentives to form spinoffs are reduced even if venture capital is readily available and the negative effect of $\gamma$ on the innovation

\footnotetext{
${ }^{5}$ For the extreme case $\gamma=1$ spinoff founders obtain venture capital without any sharing of profits. Obviously this is not a realistic scenario and should be considered as a theoretical benchmark.
} 


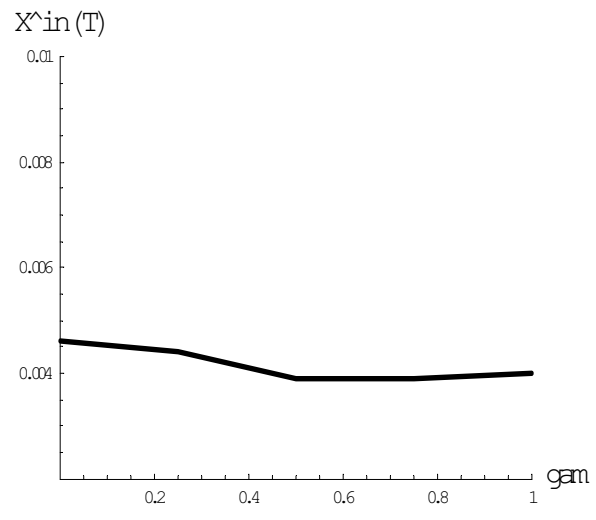

(a)

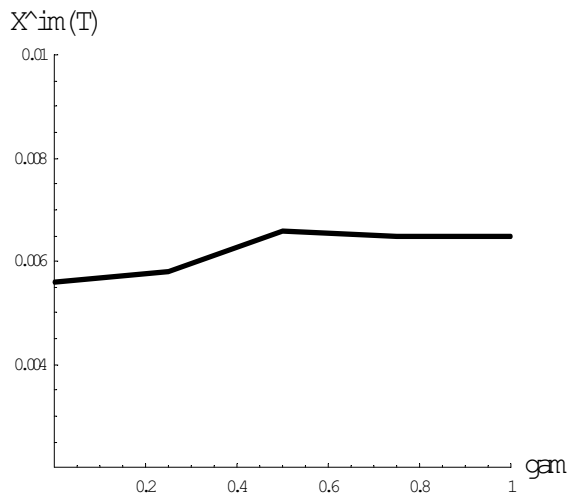

(b)

Figure 3: Average innovation expenditures (a) and imitation expenditures (b) per unit of capital for $\beta=\eta=0$.

incentives are smaller than in the baseline case. It turns out that quite the opposite is true. In figure 5 we compare innovation and imitation expenditures depending on $\gamma$ for $\eta=0,0.05,0.1$ and $\beta=0$. It can be clearly seen that the negative effect of $\gamma$ on innovation expenditures becomes stronger if there are positive learning curve effects. A possible explanation for this pattern is that the bonus firms have to pay in order to prevent the formation of a spinoff after a radical innovation does not only depend on the potential profits of the spinoffs but also on the expected losses by the incumbent. Given that incumbents on average have lower per unit costs the stronger the learning curve effects, strong learning curve effects imply that the negative impact on profits of the productivity losses implied by a spinoff formation is strong. Accordingly, the larger $\eta$ is, the higher are the bonus payments needed to prevent spinoff formation. This effect increases the incentives of firms to acquire the technology by subsequent imitation rather than preventing the spinoff from forming and we obtain a shift of expenditures towards imitative activities. This shift becomes stronger the more likely it is that spinoffs form. For $\eta=0.1$ and $\gamma=1$ firms on average spend three times as much for imitation than for innovation.

The impact of positive learning curve effects on productivity, profits and industry concentration is now quite obvious (figure 6). As has to be expected increasing learning curve effects yield an upward shift of the lines indicating average profits and industry concentration. This induces an increase in average expenditures for innovation and imitation and therefore also average productivity goes up. With respect to the impact of changes in the availability of venture capital we observe that the addition of learning 


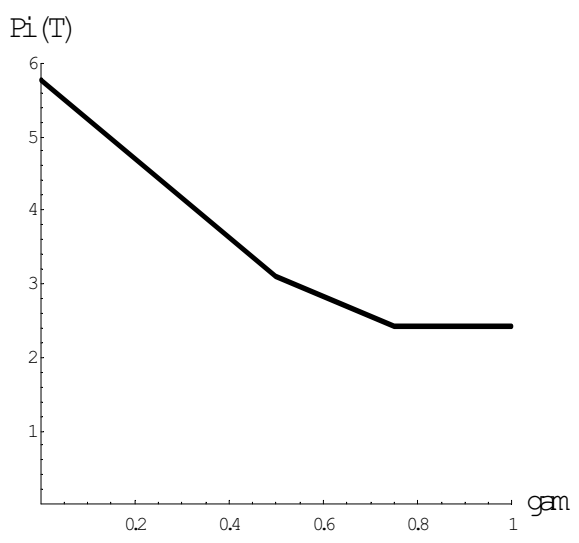

(a)

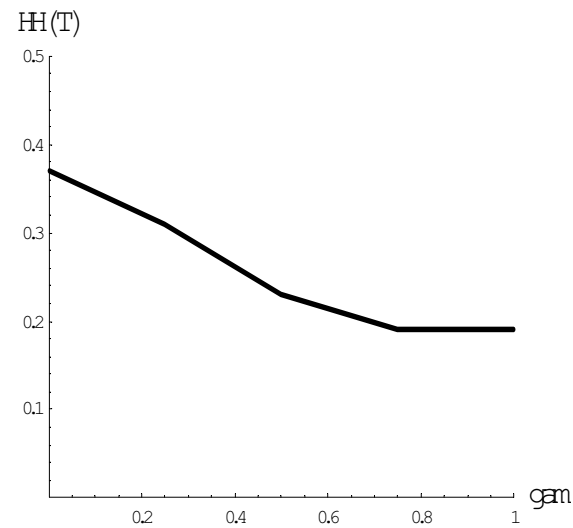

(b)

Figure 4: Average firm profits (a) and industry concentration (b) at period $T$ for $\beta=\eta=0$.

curve effects does not qualitatively alter the observations made in the baseline case but rather reinforces these phenomena. Productivity, profits and industry concentration decrease if the $\gamma$ goes up.

\subsection{The Impact of Technological Spillovers}

If there are technological spillovers within a cluster firms profit from innovative activities of the other enterprises in the cluster. Taking this externality into account, the formation of a spinoff has an inter-temporal positive effect for the incumbent in addition to the negative effects due to current knowledge losses and increased competition.

We study the impact of this positive inter-temporal effect by comparing the baseline case with scenarios where the spillover parameter is increased to $\beta=0.2$ and $\beta=0.4$ but no learning curve effects are present. As can be seen in figure 7 the presence of technological spillovers indeed substantially changes the impact of availability of venture capital on the balance between innovation and imitation expenditures. We now observe that expenditures for innovation increase whereas expenditures for imitation decrease as $\gamma$ goes up. For $\beta=0.4$ and $\gamma=1$ firms spend almost twice as much for innovation as for imitation. Due to the spillovers firms in large clusters on average have to spend less own funds in order to generate a successful innovation. Therefore the return on investment for innovation in large cluster is comparatively large and firms shift expenditures from imitation to innovation.

The shift of expenditures towards innovative activities improves the speed of tech- 


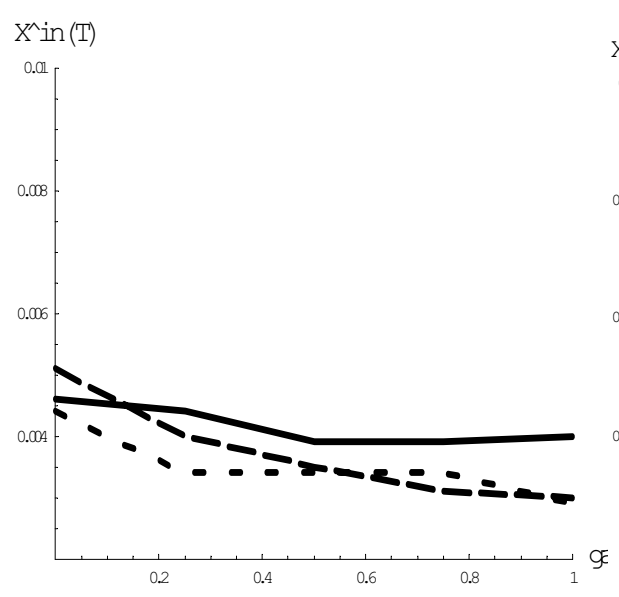

(a)

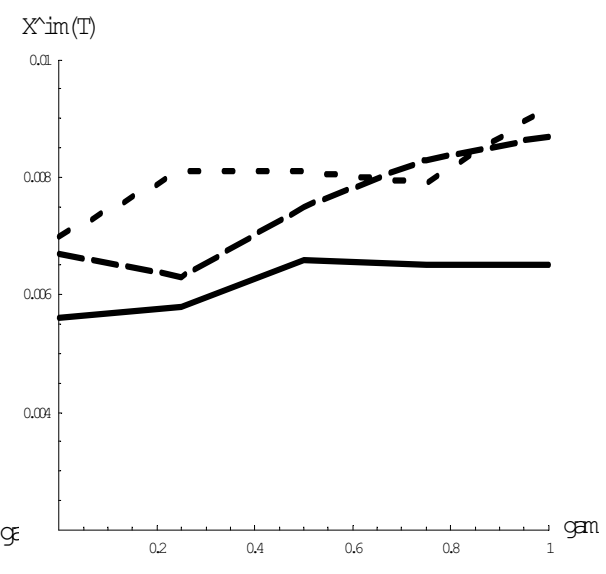

(b)

Figure 5: Average innovation expenditures $X^{i n}(T)$ and imitation expenditures $X^{i m}(T)$ per unit of capital for $\eta=0$ (solid line), $\eta=0.05$ (dashed line) and $\eta=0.1$ (dotted line); $\beta=0$.

nological change. Figure 8 shows that with positive technological spillovers an increase in the availability of venture capital has a positive impact on the average productivity. This does not translate into a positive impact of $\gamma$ on average firm profits due to decreased industry concentration and increased intensity of competition induced by an increase in $\gamma$. In particular, for large values of $\gamma$ the industry reaches a significantly higher productivity than in the baseline case but average firm profits for $\beta=0.4$ are less than $50 \%$ compared to the case where $\beta=0$. The main reason for this observation is that with spillovers more (radical) innovations are developed and more spinoffs are founded. Accordingly, industry concentration is smaller in the presence of spillovers and this has effects on profits. Introspection of individual simulation runs shows that although the final concentration of the industry is rather small for large values of $\gamma$, typically a dominant cluster emerges and all firms that end up with a significant market share are members of this cluster. Also firms that are founded relatively late in the dominant cluster may become one of the leading producers. This is quite in contrast to the scenarios with learning curve effects and no spillovers, where introspection of single runs shows that the industry is typically dominated by incumbents and early spinoffs.

Although the focus of this analysis is on the evolution of productivity, industry structure and firms' innovation strategies, at this point we should briefly discuss consumer surplus. If we consider total industry output in dependence of the parameter $\gamma$, we observe a strong positive relationship. This is the result of increasing average productivity and increasing intensity of competition. Accordingly, the price of the 


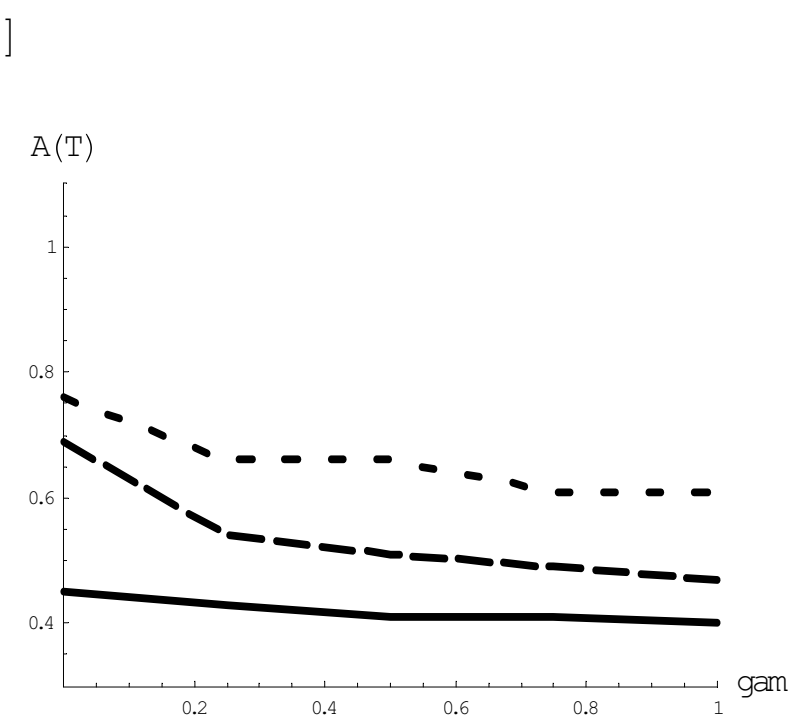

(a)

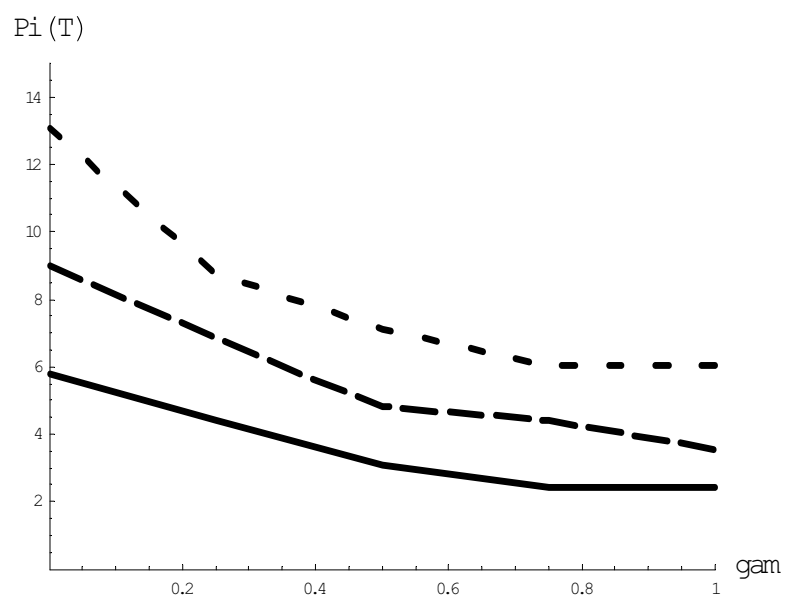

(b)

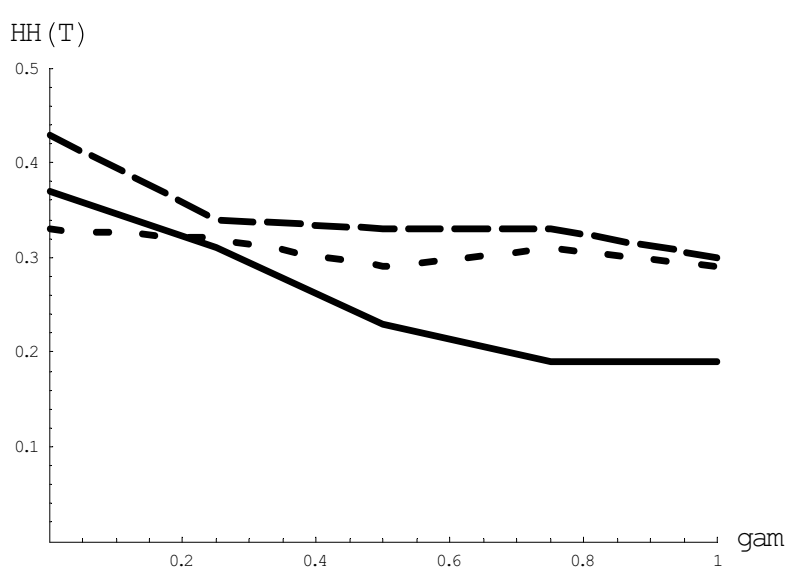

(c)

Figure 6: Average productivity (a), average profits (b) and industry concentration (c) after $T$ periods for $\eta=0$ (solid line), $\eta=0.05$ (dashed line) and $\eta=0.1$ (dotted line); $\beta=0$. 


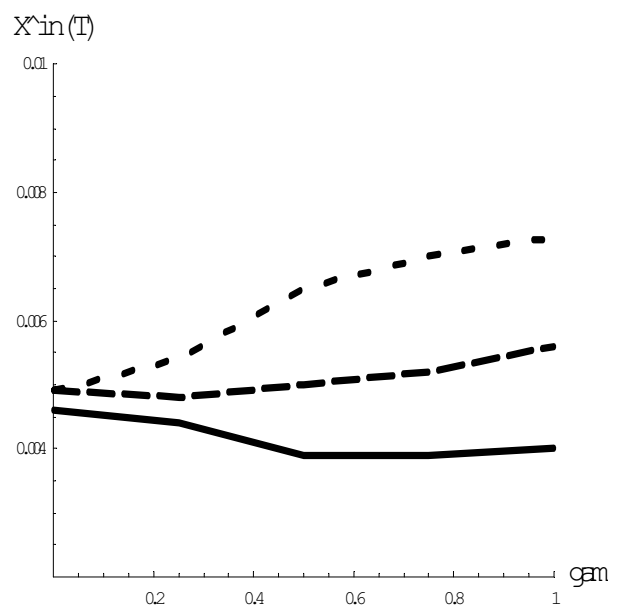

(a)

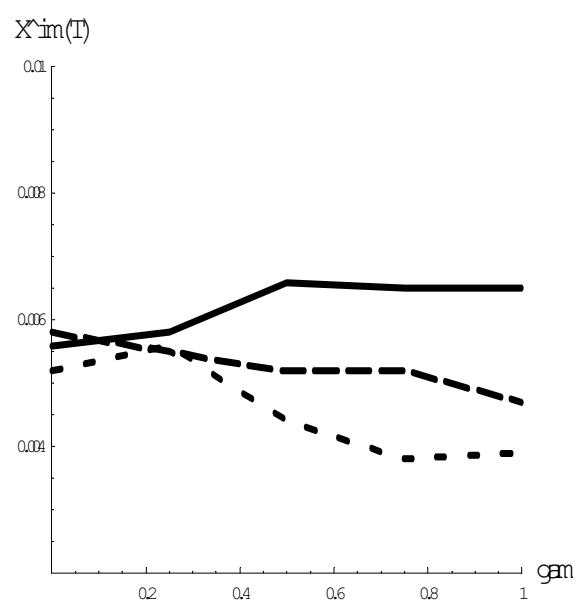

(b)

Figure 7: Average innovation expenditures $X^{i n}(T)$ and imitation expenditures $X^{i m}(T)$ per unit of capital for $\beta=0$ (solid line), $\beta=0.2$ (dashed line) and $\beta=0.4$ (dotted line); $\eta=0$.

consumption good decreases as $\gamma$ increases. This means that improved availability of venture capital decreases average firm profits but improves the speed of technological change and consumer surplus.

\subsection{The Interplay of Learning Curve Effects and Technological Spillovers}

In the previous subsections we have seen that the qualitative impact of an increase of $\gamma$ on expenditures for innovation and on the speed of technological change alters significantly depending on whether technological spillovers and learning curve effects are present or not. On the other hand, the effect of an increase in $\gamma$ on profits and industry concentration was always negative. Given these findings we should expect a negative impact of $\gamma$ on these two variables also if both effects are simultaneously present. Furthermore, it is quite clear that in such a case the dependency of average productivity and average innovation expenditures on $\gamma$ will in general depend on the relative strength of the two effects and can be non-monotonous. In particular, there might be an interior value of $\gamma$ that maximizes the speed of technological change in an industry. To illustrate this point we show in figure 9 the dependence of average productivity and average innovation expenditures on $\gamma$ for the parameter setting $\beta=0.2, \eta=0.05$.

Although the strategic effect is large enough to generate a negative relationship between $\gamma$ and innovation expenditures, the additional knowledge externalities generated by increased spinoff formations are sufficiently strong such that average productivity 


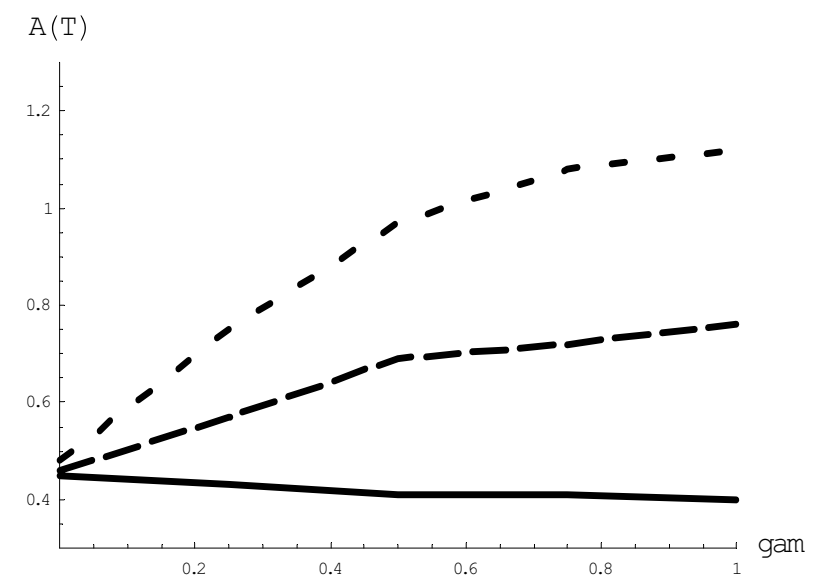

(a)

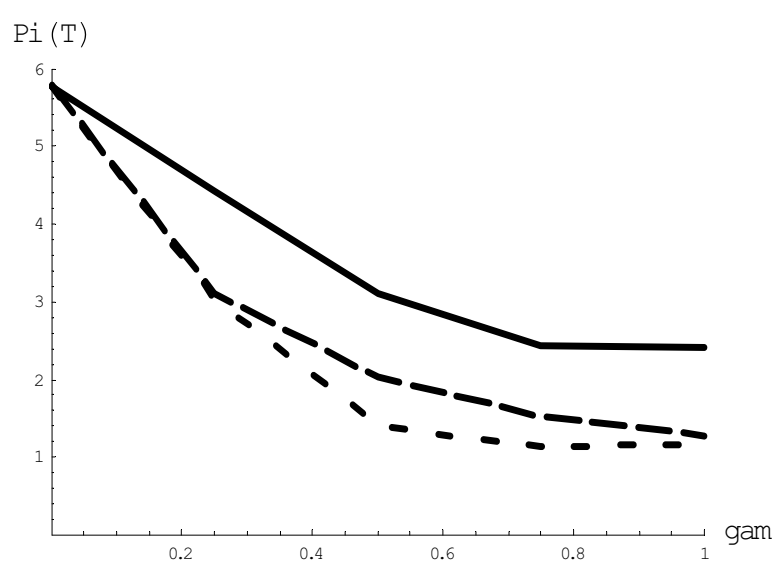

(b)

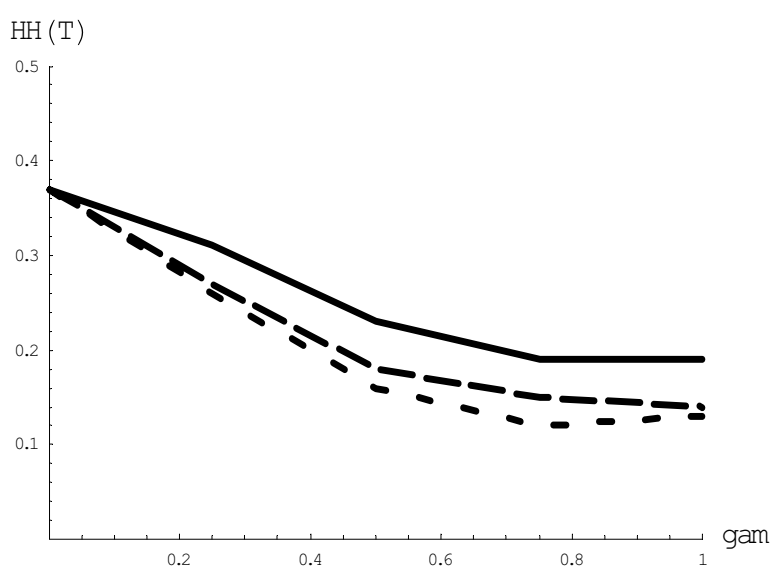

(c)

Figure 8: Average productivity (a), average profits (b) and industry concentration (c) after $T$ periods for for $\beta=0$ (solid line), $\beta=0.2$ (dashed line) and $\beta=0.4$ (dotted line); $\eta=0$. 


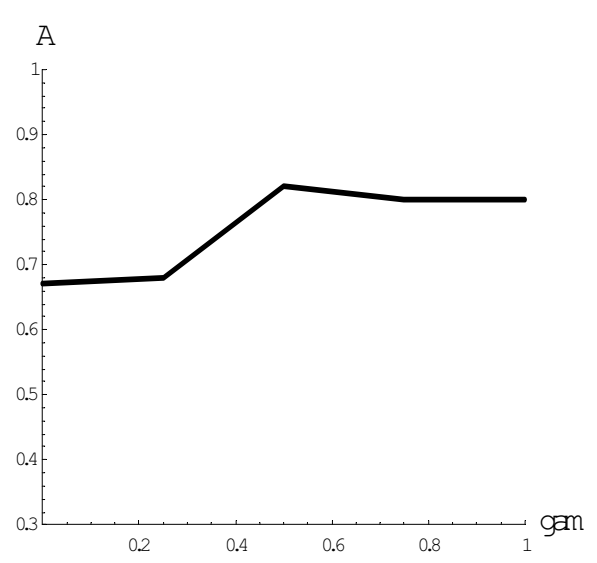

(a)

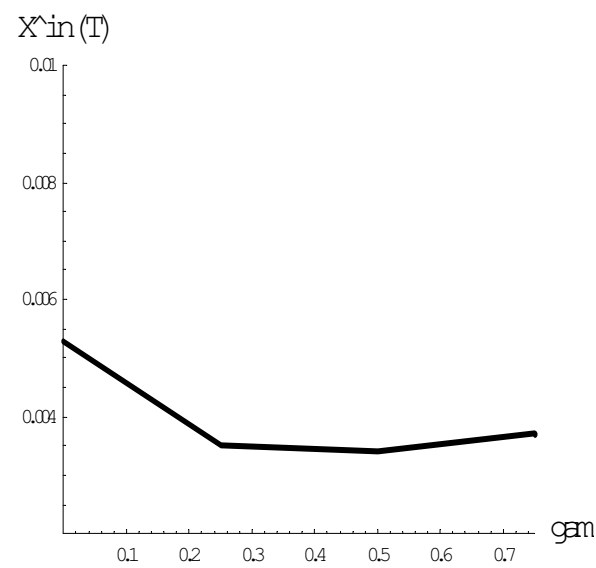

(b)

Figure 9: Average productivity (a) and average innovation expenditures after $T$ periods for $\eta=0.05$ and $\beta=0.2$.

is increasing with $\gamma$ for small values of that parameter. Also in this case the difference in average productivity between runs with $\gamma=0$ and such with $\gamma=1$ is statistically significant. The highest median of average productivity values is reached for $\gamma=0.5$. Accordingly, in such a scenario there can be both too much venture capital and too little venture capital. More substantial statements could only be made with particular industries in mind where the relative strength of the two considered effects could be estimated. Such an exercise is beyond the scope of this paper.

\section{Conclusions}

The agenda of this paper is to gain a better understanding of the interplay of different effects generated by easy availability of venture capital on the speed of technological change and the evolution of an industry. The two main effects under consideration are a positive direct effect ( $\mathrm{VC}$ facilitates the emergence of industrial clusters and therefore generates positive externalities through local technological spillovers) and a negative incentive effect (VC improves the outside option of potential spinoff founders which reduces the expected return on $\mathrm{R} \& \mathrm{D}$ investments for incumbents).

Based on the results of our industry simulations we can conclude that it depends crucially on the characteristics of the considered industry which of these two effects dominates. In particular, if there are no knowledge flows between spinoffs and their parent companies after the spinoffs have been found, the effect of the additional in- 
novation expenditures funded by the capital flowing into the industry is outweighed by the downward adaptation of innovation intensities by the incumbent firms. Easier access to venture capital by potential spinoff founders induces slower growth of the average productivity in the industry. Presence of learning curve effects or other comparative advantages for incumbents reinforce this phenomenon since prevention of spinoff formation becomes very costly and the focus of incumbents shifts towards imitative activities. If there are sufficiently strong technological spillovers between parents and spinoffs after spinoff formation, the negative relationship between innovation intensity and venture capital availability disappears. Based on past experience firms anticipate future positive effects of an increase in their cluster due to spinoff formation and these effects outweigh the reduced appropriability due to thicker venture capital markets. If spillover effects are not so strong, innovation intensities go down as venture capital markets become thicker but due to increased knowledge externalities average industry productivity still goes up.

The approach in this paper is a theoretical one and we do not intend to capture the structure of any particular industry with the considered model ${ }^{6}$, but rather are interested in obtaining general insights. Nevertheless, our findings yield testable conjectures about the relationship between venture capital investments, number of spinoffs, innovation intensity and productivity growth in different types of industries. We will attempt to empirically test these conjectures in future work.

\section{References}

Anand, B. and A. Galetovic (2000), 'Weak Property Rights and Holdup in R\&D', Journal of Economics and Management Strategy, 9, 615-642.

Baccara, M. and R. Razin (2004), 'Curb Your Innovation: Corporate Conservatism in the Presence of Imperfect Intellectual Property Rights', Working Paper, New York University.

Botazzi, L., Da Rin, M. and T. Hellmann (2004), 'The Changing Face of the European Venture Capital Industry: Facts and Analysis', Journal of Private Equity, 7, 2653.

Böhm, V. and L. Colombo (2006), 'Technology Choice with Externalities - A General Equilibrium Approach', Working Paper, Bielefeld University.

Colombo, L. and H. Dawid (2006), 'Do Thick Ventrue Capital Markets Foster Innovation? A Strategic Analysis', Mimeo, Bielefeld University.

Dahl, M.S., Pedersen, C.O.R., and B. Dalum (2003), 'Entry by Spinoff in a High-tech Cluster', DRUID Working Paper No. 03-11.

Dawid, H. (2006), 'Agent-based Models of Innovation and Technological Change', in L. Tesfatsion and K. Judd (eds.), Handbook of Computational Economics, Volume 2: Agent-Based Computational Economics, North-Holland, pp. 1235-1272.

\footnotetext{
${ }^{6}$ Examples of a very specific simulation model of the evolution and spinoff formation in a particular industry, the PC industry, are Malerba et al. (1999, 2001).
} 
Dorfman, N.S. (1983), 'Route 128: The development of a regional high technology economy', Research Policy, 12, 299-316.

Dosi, G., Marsili, O., Orsenigo, L. and R. Salvatore (1995), 'Learning, market selection and the evolution of industrial structures', Small Business Economics, 7, 411-436.

Gersbach, H. and A. Schmutzler (2003), 'Endogenous spillovers and incentives to innovate', Economic Theory, 21, 59-79.

Gompers, P., Lerner, J. and D. Scharfstein (2003), 'Entrepreneurial Spawning: Public Corporations and the Genesis of New Ventures', 1986-1999 ,Harvard NOM Working Paper No. 03-37.

Hellmann, T. and M. Puri (2002), 'Venture Capital and the Professionalization of Start-Up Firms: Empirical Evidence', Journal of Finance, LVII, 169-197.

Malerba, F. and L. Orsenigo (1996), 'The dynamics and evolution of industries', Industrial and Corporate Change, 5, 51-87.

Nelson, R.R. and S.G. Winter (1982), An Evolutionary Theory of Economic Change (Belknap, Cambridge, MA).

Klepper, S. (1996), 'Entry, exit, growth, and innovation over the product life cycle', American Economic Review, 86, 562-583.

Klepper, S. (2004), 'Agglomeration through Spinoffs: How Detriot became the capital of the U.S. Automobile Industry', Working Paper, Carnegie Mellon University.

Malerba, F., Nelson, R., Orsenigo, L. and S. Winter (1999), 'History-friendly models of industry evolution: the computer industry', Industrial and Corporate Change, $8,3-40$.

Malerba, F., Nelson, R., Orsenigo, L. and S. Winter (2001), 'Competition and industrial policies in a "history-friendly" model of the evolution of the computer industry', International Journal of Industrial Organization, 19, 635-664.

Pakes, A. and S. Nitzan (1983), 'Optimum Contracts for Research Personnel, Research Employment and the Establishment of "Rival" Enterprises', Journal of Labor Economics, 1, 345-365.

Philipps, D.J. (2002), 'A Genealogical Approach to Organizational Life Chances: The Parent-Progeny Transfer among Silicon Valley Law Firms, 19461-996', Administrative Science Quarterly, 47, 474-506.

Sorenson, O. (2003), 'Social Networks and Industrial Geography', Journal of Evolutionary Economics, 13, 513-527.

Sorenson, O. and T.E. Stuart (2001), 'Syndiaction Networks and the Spatial Distribution of Venture Capital Investments', American Journal of Sociology, 106, 1546-1588. 